\title{
Reduced Reaction Mechanism for Rocket Nozzle Ablation Simulations
}

\author{
Peter G. Cross* \\ Naval Air Warfare Center Weapons Division, China Lake, CA, 93555 \\ Iain D. Boyd ${ }^{\dagger}$ \\ University of Michigan, Ann Arbor, MI, 48109
}

\begin{abstract}
A reduced reaction mechanism suitable for modeling finite-rate gas-phase chemistry associated with the ablation of carbon-phenolic materials in rocket nozzle applications is presented. Important species are identified by performing equilibrium chemistry calculations over a range of conditions determined from decoupled ablation analyses of the HIPPO nozzle. An investigation of the literature is performed to identify candidate reaction mechanisms that involve these species. Sensitivity studies are conducted in order to reduce a large combustion mechanism to a minimal essential set of species and reactions that can accurately model the post-combustion nozzle core flow and ablation products over the conditions of interest. This reduced mechanism is small (only 20 species and 33 reactions) so that it can be utilized in a flow solver as part of conjugate ablation analyses of rocket nozzles. This mechanism is found to be adequate for modeling the flow through the nozzles of solid rocket motors using typical aluminized AP/HTPB propellants, and should be suitable for use in conjugate flowfield/ablation analyses of carbon-phenolic nozzles for nondimensional pyrolysis gas mass flux values up to 0.4 , temperatures up to $3000 \mathrm{~K}$, and pressures up to 6.0 MPa.
\end{abstract}

\section{Nomenclature}

$\begin{array}{ll}A & \text { Pre-exponential factor, } \mathrm{mol}-\mathrm{cm}-\mathrm{s} \\ b & \text { Temperature exponent } \\ B^{\prime} & \text { Nondimensional mass flux } \\ k & \text { Reaction rate coefficient, } \mathrm{mol}-\mathrm{cm}-\mathrm{s} \\ P & \text { Pressure, Pa } \\ S & \text { Normalized sensitivity coefficient } \\ T & \text { Temperature, } \mathrm{K} \\ X & \text { Sensitivity parameter } \\ Y & \text { Mass fraction } \\ \text { Subscripts } \\ a & \text { Activation } \\ c & \text { Char } \\ e & \text { Edge gas } \\ g & \text { Pyrolysis gas } \\ i & \text { The } i \text { th species } \\ r & \text { The } r \text { th reaction }\end{array}$

\footnotetext{
*Aerospace Engineer, Aeromechanics \& Thermal Analysis Branch, 1900 N. Knox Road, M/S 6622, AIAA Senior Member.

${ }^{\dagger}$ James E. Knott Professor, Department of Aerospace Engineering, 1320 Beale Ave., AIAA Fellow.
} 


\section{Introduction}

Performing conjugate analyses of ablation in rocket nozzles requires a gas-phase reaction mechanism that includes both nozzle core flow species as well as ablation product species. The reaction mechanism proposed by Troyes et al.1 was developed to model rocket plumes, but has been found to adequately model the nozzle flow for solid rocket motors using typical aluminized AP/HTPB (ammonium perchlorate / hydroxyl-terminated polybutadiene) propellants. ${ }^{2}$ However, this mechanism does not include several species (e.g. $\mathrm{CH}_{4}, \mathrm{C}_{2} \mathrm{H}_{2}$ ) that are important products present at the ablating surfaces of carbon-phenolic materials. Martin et al. 3 reviewed three existing mechanisms, and introduced a fourth, for modeling ablation of carbonphenolic materials in air. Unfortunately, all of these mechanisms exclude chlorine-containing species that are important for solid rocket motor flows. Likewise, the mechanism proposed by Gökçen ${ }^{4}$ does not contain important chlorine-containing species. Therefore, a new reduced mechanism is proposed to fill the need presented by conjugate ablation analyses.

This paper begins with a series of studies that identify the species most relevant to the ablation of carbonphenolic materials within solid rocket motors using aluminized AP/HTPB propellants. The literature is then reviewed to identify a baseline, detailed chemical kinetics mechanism involving all relevant species. Sensitivity analyses are performed on the baseline mechanism, over a range of relevant conditions, in order to identify the key reactions and species that are important for nozzle ablation problems. The accuracy of this reduced mechanism is assessed by comparing results produced by the detailed and reduced mechanisms. The reduced mechanism identified in this effort contains 20 species and 33 reactions, and produces results in good agreement with the much larger baseline mechanism. Finally, this reduced mechanism is used to model the flow through the HIPPO nozzle; results compare favorably with those obtained using the Troyes mechanism and a equilibrium chemistry reference solution.

\section{Species Selection}

\section{II.A. Carbon-Phenolic Ablation}

To identify the species relevant to ablation in rocket nozzles, a decoupled ablation analysis is performed for the HIPPO 5 nozzle. Convective boundary conditions along the nozzle are computed with the LeMANS flow solver, while the ablation response is computed using the MOPAR-MD2, 7 material response solver. Additional details of the HIPPO nozzle test case and the decoupled ablation analysis methodology are presented by Cross and Bovd 2 and for brevity are not repeated here. Six surface probe points are spaced along the nozzle (see Fig. 1); temperature, pressure, and non-dimensional pyrolysis gas mass flux $B_{g}^{\prime}$ are recorded as a function of time for the duration of the motor operation. From these data it is possible to determine the region of the "parameter space" in $\left(T, P, B_{g}^{\prime}\right)$ that would be encountered by the nozzle.

Plots of the parameter space are given in Fig. 2 through Fig. 1. From Fig. 2 it can be seen that the temperature that is experienced is fairly insensitive to the pressure, though higher pressures are generally

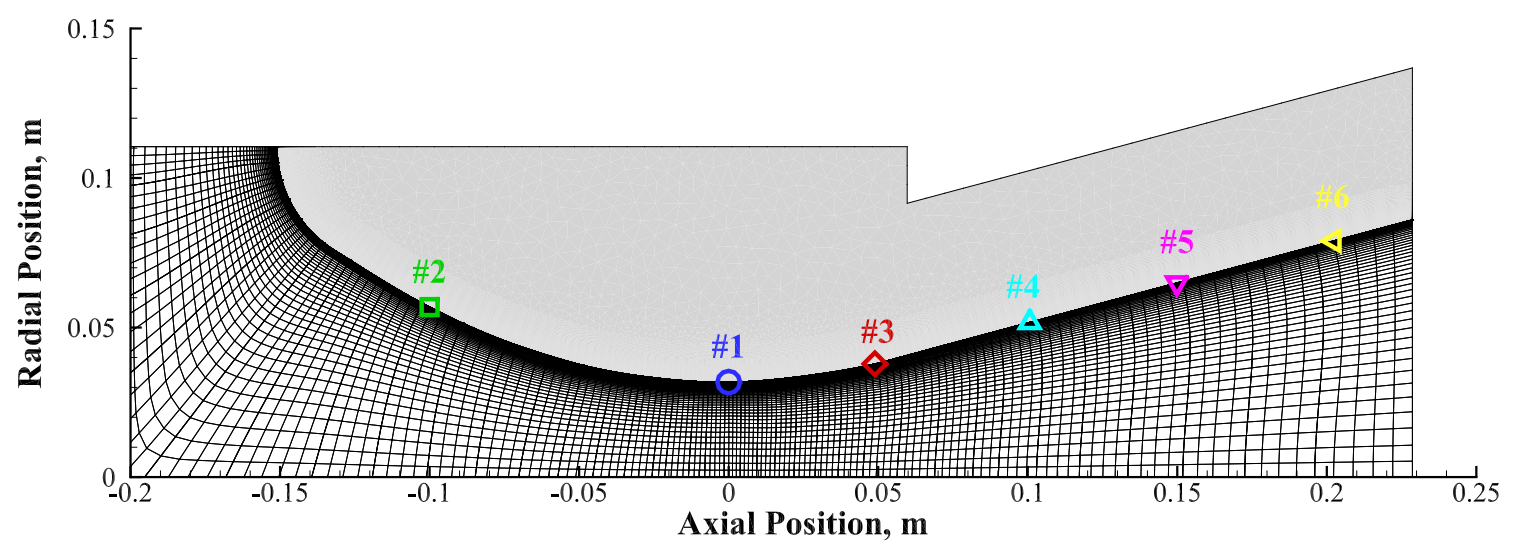

Figure 1. Geometry of the HIPPO nozzle. Shaded region is the material response solver domain, with the six probe points indicated. Mesh in the flow solver domain is also illustrated. 


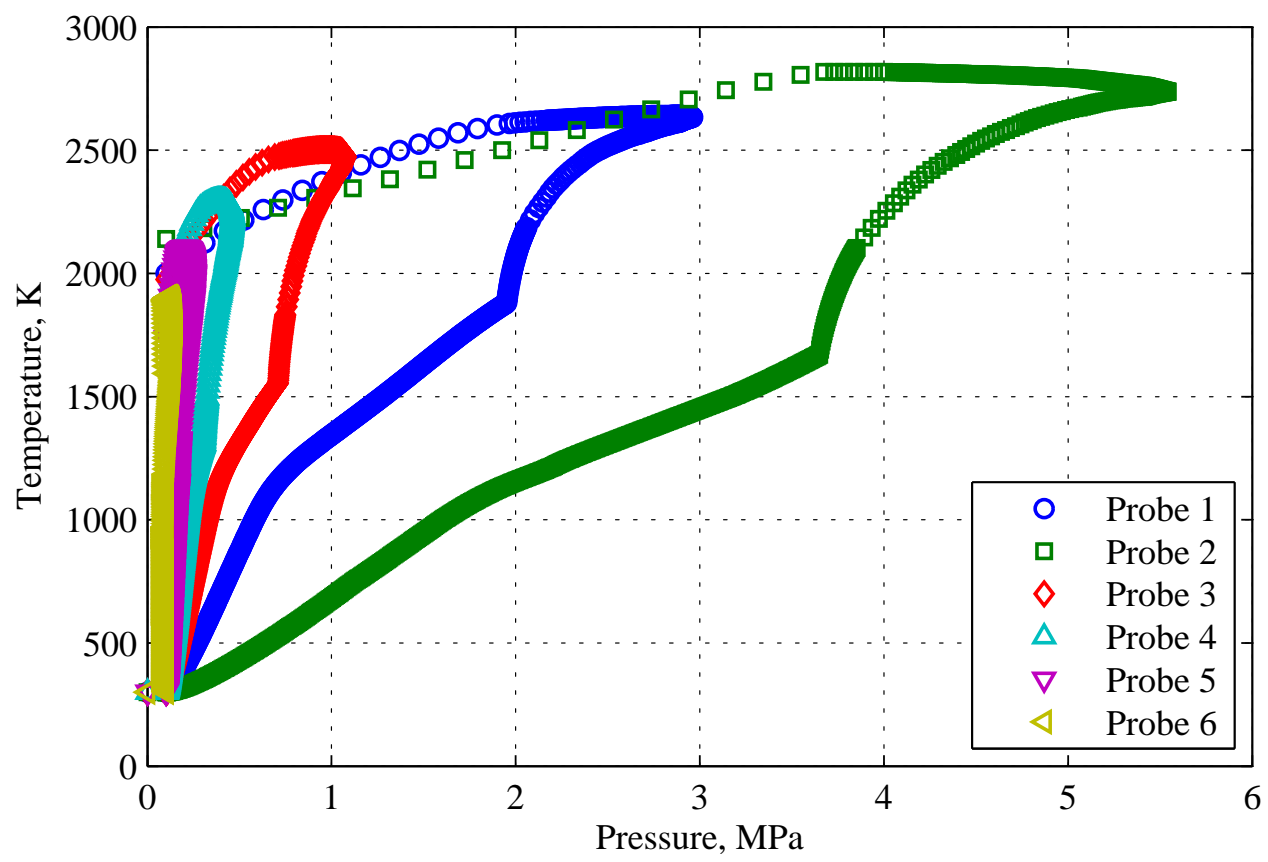

Figure 2. The temperature - pressure parameter space encountered by the HIPPO nozzle.

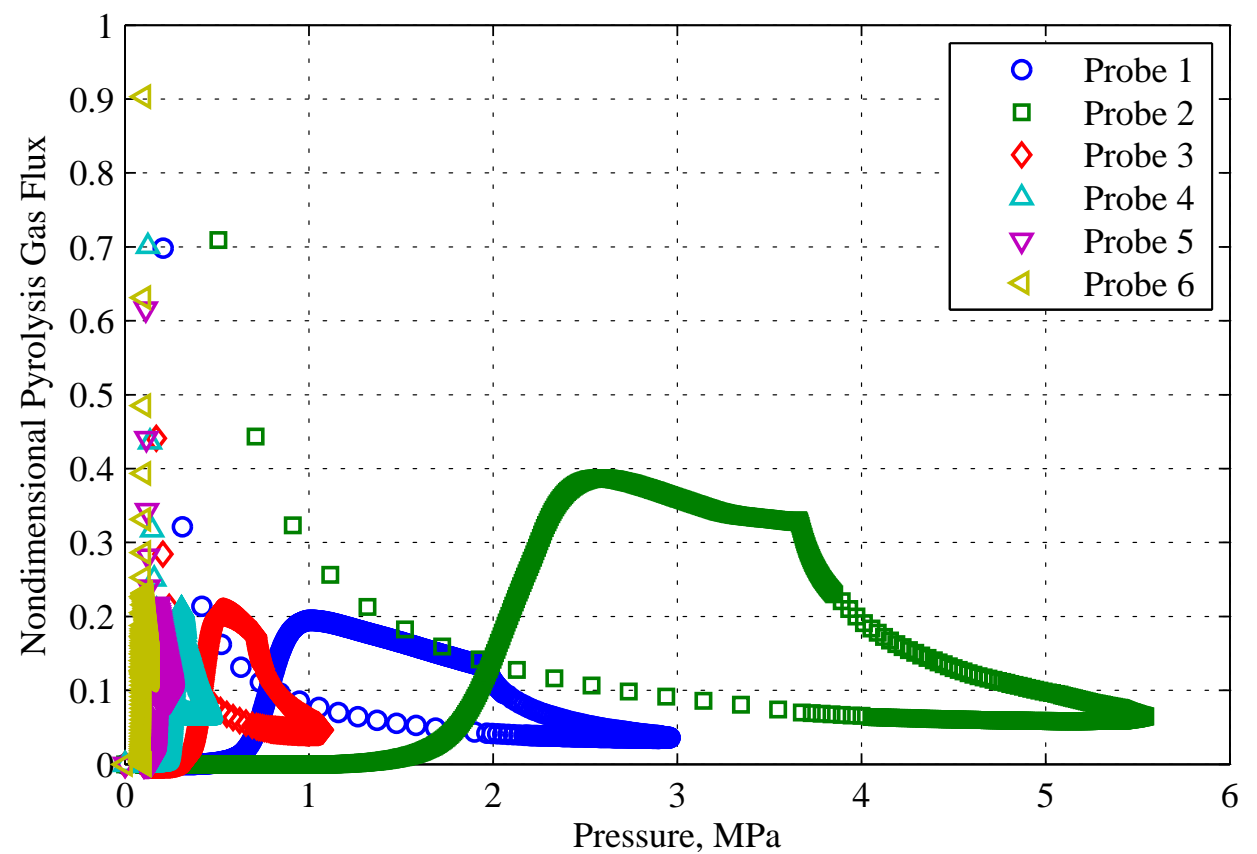

Figure 3. The nondimensional pyrolysis gas flux - pressure parameter space encountered by the HIPPO nozzle. 


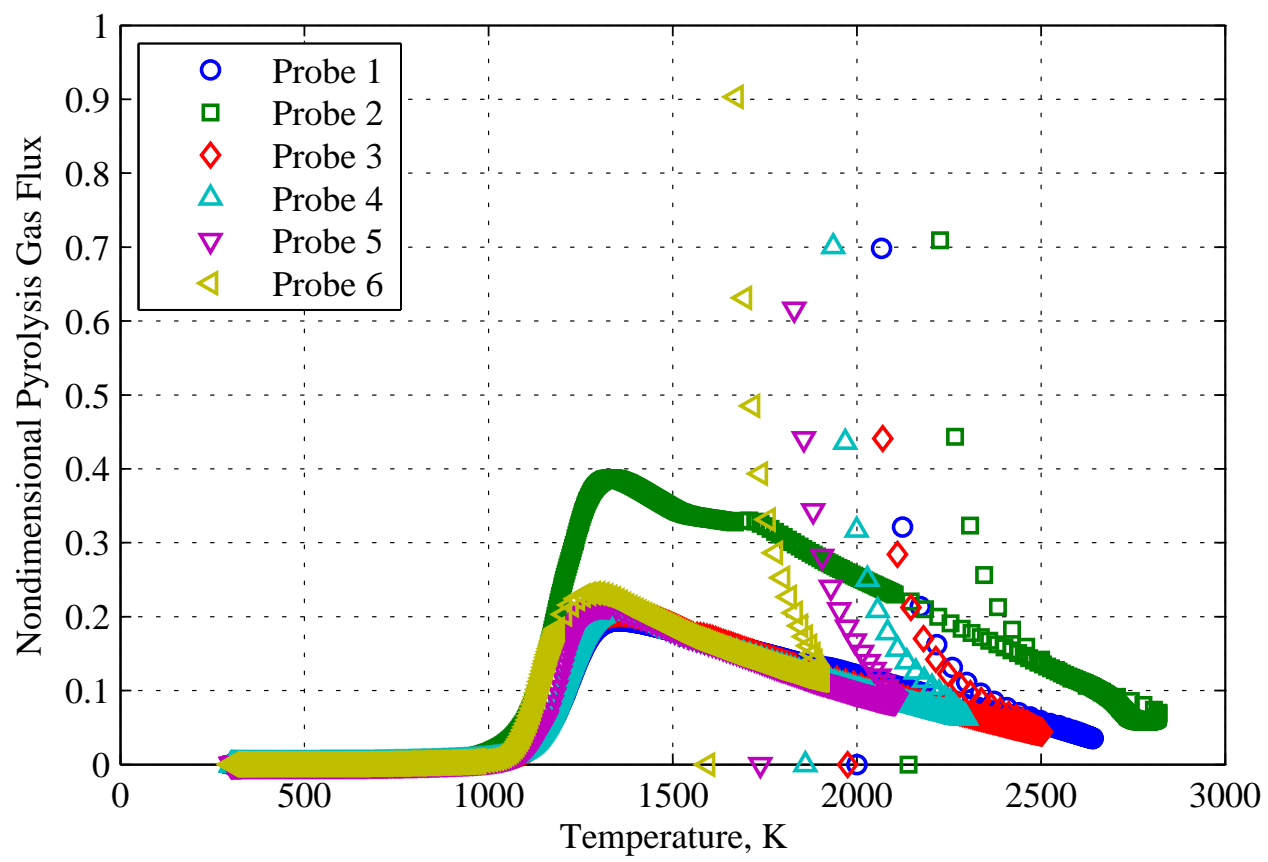

Figure 4. The nondimensional pyrolysis gas flux - temperature parameter space encountered by the HIPPO nozzle.

associated with higher temperatures. From Fig. 3 it seems that the value of $B_{g}^{\prime}$ that can be achieved is also fairly insensitive to pressure. However, in Fig. 4 it can be seen that $B_{g}^{\prime}$ does have some dependence on temperature, e.g. for $B_{g}^{\prime}>0$ the temperature must be about $1000 \mathrm{~K}$ or greater. Note that there are a few points with $B_{g}^{\prime}>1$ (off the limits of these plots).

Based on these plots, it is possible to establish the range of parameters for two different studies identifying important ablation product species. Together, these studies cover virtually all of the ablating parameter space encountered by the HIPPO nozzle. The parameters for the first study are:

$$
\begin{gathered}
B_{g}^{\prime}=0 \\
T=[300: 100: 3000] \mathrm{K} \\
P=[0.1,0.2,0.5,1.0,2.0,5.0,6.0] \mathrm{MPa}
\end{gathered}
$$

(where the convention [initial value : increment value : final value] is used) for a total of 196 points in the parameter space. For the second study the parameters are:

$$
\begin{gathered}
B_{g}^{\prime}=[0.0,0.001,0.01,0.1,0.2,0.3,0.4] \\
T=[500: 250: 3000] \mathrm{K} \\
P=[0.1,0.2,0.5,1.0,2.0,5.0,6.0] \mathrm{MPa}
\end{gathered}
$$

(539 points total). The Chemics 8 chemical equilibrium code (using the $\mathrm{CEA}^{9}$ thermodynamics database) is used to compute the resultant species mass fractions for each set of conditions in these two studies. Additional inputs required by the Chemics code are the elemental composition of the edge gases (nozzle core flow), the pyrolysis gases, and the char, obtained from Arnold et al. 5 and presented in Table 1 .

\section{II.B. Nozzle Core Flow}

A third study is performed, to determine the relevant species within the nozzle core flow separate from ablation. The parameters for this study are:

$$
\begin{gathered}
T=[1000: 100: 3500] \mathrm{K} \\
P=[0.1,0.2,0.5,1.0,2.0,5.0,6.0] \mathrm{MPa}
\end{gathered}
$$


Table 1. Elemental mass fractions for the propellant, the nozzle edge gases (propellant gas-phase combustion products), the pyrolysis gases, and the char for the HIPPO nozzle.

\begin{tabular}{ccccc}
\hline Element & Propellant & Edge Gas & Pyrolysis Gas & Char \\
\hline $\mathrm{H}$ & 0.03752 & 0.05378 & 0.10710 & 0.0 \\
$\mathrm{C}$ & 0.11304 & 0.16203 & 0.60957 & 1.0 \\
$\mathrm{~N}$ & 0.08793 & 0.12603 & 0.0 & 0.0 \\
$\mathrm{O}$ & 0.39027 & 0.35539 & 0.28333 & 0.0 \\
$\mathrm{Al}$ & 0.16001 & 0.0 & 0.0 & 0.0 \\
$\mathrm{Cl}$ & 0.21123 & 0.30277 & 0.0 & 0.0 \\
\hline
\end{tabular}

Table 2. List of important species identified for the ablating HIPPO nozzle, along with the number of points in the three studies at which they are determined to be significant. Parentheses around index number signifies species that could probably be neglected, as discussed in the text. Note that $\mathrm{Al}_{2} \mathrm{O}_{3}^{\star}$ is an inert condensed-phase species.

\begin{tabular}{|c|c|c|c|c|}
\hline Index & Species & Study 1 & Study 2 & Study 3 \\
\hline 1 & $\mathrm{CH}_{4}$ & 115 & 330 & 20 \\
\hline$(2)$ & $\mathrm{CN}$ & 1 & 7 & - \\
\hline 3 & $\mathrm{CO}$ & 168 & 490 & 182 \\
\hline 4 & $\mathrm{CO}_{2}$ & 95 & 235 & 182 \\
\hline$(5)$ & $\mathrm{C}_{2} \mathrm{H}$ & 1 & 10 & - \\
\hline 6 & $\mathrm{C}_{2} \mathrm{H}_{2}$ & 63 & 225 & - \\
\hline (7) & $\mathrm{C}_{2} \mathrm{H}_{4}$ & - & 13 & - \\
\hline (8) & $\mathrm{C}_{4} \mathrm{H}_{2}$ & 7 & 49 & - \\
\hline (9) & $\mathrm{C}_{6} \mathrm{H}_{6}$ & - & 1 & - \\
\hline 10 & $\mathrm{Cl}$ & 51 & 153 & 84 \\
\hline 11 & $\mathrm{H}$ & 15 & 55 & 36 \\
\hline 12 & $\mathrm{H}_{2}$ & 170 & 302 & 182 \\
\hline 13 & $\mathrm{H}_{2} \mathrm{O}$ & 99 & 163 & 182 \\
\hline 14 & $\mathrm{HCN}$ & 97 & 539 & - \\
\hline 15 & $\mathrm{HNC}$ & 49 & 488 & - \\
\hline 16 & $\mathrm{HCl}$ & 196 & 244 & 182 \\
\hline 17 & $\mathrm{~N}_{2}$ & 196 & 539 & 182 \\
\hline 18 & NO & - & - & 15 \\
\hline 19 & $\mathrm{O}$ & - & - & 18 \\
\hline 20 & $\mathrm{O}_{2}$ & - & - & 10 \\
\hline 21 & $\mathrm{OH}$ & - & - & 56 \\
\hline 22 & $\mathrm{Al}_{2} \mathrm{O}_{3}^{\star}$ & - & - & 182 \\
\hline
\end{tabular}

5 of 18 
yielding 182 points. The Chemics program is again used to compute the species mass fractions; the elemental composition of the propellant (Table 1) is another added input. All aluminum is assumed to react with oxygen to form condensed-phase $\mathrm{Al}_{2} \mathrm{O}_{3}^{\star}$.

\section{II.C. Selected Species}

The species mass fraction data produced by Chemics for each point in each study is post-processed to identify those species with mass fractions at or above a threshold value. For this work a threshold value of $0.001(0.1 \%)$ is used. The error incurred by excluding species with mass fractions less than this threshold value is expected to be acceptable (errors on the order of $2 \%$ or less are generally considered acceptable for computational fluid dynamics solutions). The number of points at which each species is identified as being significant is computed. A list is constructed for each study, tabulating those species which are identified as being significant, along with the number of points in the study where they are deemed to be significant.

The results from these three studies are summarized in Table 2. A total of 22 species are identified as being potentially significant; note that $\mathrm{Al}_{2} \mathrm{O}_{3}^{\star}$ is an inert condensed-phase species. With additional consideration several of these can be eliminated. $\mathrm{C}_{6} \mathrm{H}_{6}$ occurs at only one point (at low pressure, and with a mass fraction equal to the threshold value of 0.001 ), so can easily be eliminated. $\mathrm{C}_{4} \mathrm{H}_{2}$ occurs at a few points for the two ablation studies, but only at the highest temperature $(3000 \mathrm{~K})$, and with a relatively small mass fraction of 0.0022 or less. Since this temperature is never quite reached in the HIPPO analysis, this species can also be eliminated. Similarly, $\mathrm{C}_{2} \mathrm{H}$ only occurs at a few points, again only at $3000 \mathrm{~K}$, and with mass fractions of 0.0017 or less; it can also be neglected. CN also only occurs at only a few points, at the lowest pressure and the highest temperature, with a small mass fraction of 0.0011 ; it can be neglected as well. Finally, $\mathrm{C}_{2} \mathrm{H}_{4}$ occurs only at a few points, at the highest value considered for $B_{g}^{\prime}(0.4)$, but for a range of pressures and temperatures. Predicted mass fraction is relatively small, at 0.0022 or less. Removal of this species is not so easy to justify as for some of the others, but the small mass fraction suggests that it could be removed with the introduction of minimal error.

\section{Reduced Kinetic Model}

\section{III.A. Baseline Mechanism}

A literature survey is performed in order to identify an existing mechanism that could potentially be used to model the species identified as being important. One mechanism that has been used in the literature 10 -12 to model the combustion of ammonium perchlorate / HTPB solid rocket propellants is the "reduced Jeppson" mechanism presented by Gross. $\frac{13}{13}$ This baseline mechanism features 127 reactions involving 37 species, including all gas-phase species identified in this work as being important for ablation of rocket nozzles (except for HNC). While this mechanism is small enough that it could conceivably be used directly in flow computations supporting ablation analyses, it contains a number of large species that are unimportant for post-combustion nozzle flow. By removing these unnecessary species and associated reactions, a smaller and more efficient mechanism can be produced that allows the flow computations to be completed much more quickly.

\section{III.B. Mechanism Reduction}

The baseline mechanism is simplified based upon the results of sensitivity analyses performed using SENKIN, 14 a tool distributed with the CHEMKIN program, 15 following the same general methodology utilized by Gökçen ${ }^{4}$ and Martin et al. ${ }^{3}$ SENKIN is used to compute the temperature and mass fraction histories for a homogeneous reacting mixture under adiabatic, constant pressure conditions. The first-order sensitivity coefficients (as computed from a linear sensitivity analysis) of the temperature and select species mass fractions with respect to the reaction rates are also output as functions of time. The normalized coefficient representing the sensitivity of parameter $X$ with respect to reaction $r$ is given by:

$$
S_{X, r}=\frac{k_{r} \frac{\partial X}{\partial k_{r}}}{X_{\max }}
$$

where the normalization factor $X_{\max }$ is the maximum value achieved for the parameter of interest over the course of the simulation. Temperature and the mass fractions for $\mathrm{CO}, \mathrm{CO}_{2}, \mathrm{H}_{2} \mathrm{O}, \mathrm{HCl}, \mathrm{CH}_{4}$, and $\mathrm{C}_{2} \mathrm{H}_{2}$

6 of 18

American Institute of Aeronautics and Astronautics 
are assumed to be the relevant parameters for the nozzle ablation problem. The numerator of Eq. (11) is a quantity obtained directly from SENKIN.

The sensitivity analysis is performed for the relevant portion of the nozzle parameter space in two studies. The first study considers flow through the nozzle in the absence of ablation; the parameter space for this study is:

$$
\begin{gathered}
T=[1000: 500: 3500] \mathrm{K} \\
P=[0.1,0.2,0.5,1.0,2.0,5.0,6.0] \mathrm{MPa}
\end{gathered}
$$

for a total of 42 points. The second study considers ablation products; the parameter space for this study is:

$$
\begin{gathered}
B_{g}^{\prime}=[0.0,0.1,0.2,0.3,0.4] \\
T=[1000: 500: 3000] \mathrm{K} \\
P=[0.1,0.2,0.5,1.0,2.0,5.0,6.0] \mathrm{MPa}
\end{gathered}
$$

for 175 points total. Initial species mass fractions are computed by appropriately mixing species sets representing the nozzle edge gases, the pyrolysis gases, and the char material (see Table 3). The nozzle edge gas species representation is the equilibrium composition at $T=300 \mathrm{~K}$ and $P=0.1 \mathrm{MPa}$, as computed by Chemics assuming that the only participating species are $\mathrm{HCl}, \mathrm{CO}_{2}, \mathrm{~N}_{2}, \mathrm{H}_{2} \mathrm{O}$, and $\mathrm{CH}_{4}$. Similarly, the pyrolysis gas representation is the equilibrium composition at the same conditions, assuming that the only participating species are $\mathrm{C}_{2} \mathrm{H}_{2}, \mathrm{CH}_{4}$, and $\mathrm{CO}_{2}$. Char is assumed to be purely carbon, which is modeled as an injection of $\mathrm{C}_{2} \mathrm{H}_{2}$ combined with a subtraction of an appropriate amount of $\mathrm{CH}_{4}$ to ensure no net hydrogen addition.

Initial species mass fractions for each point in these studies are computed as a function of $B_{g}^{\prime}$, $B_{c}^{\prime}$, and these three species sets according to: 16,17

$$
Y_{i}=\frac{Y_{i_{e}}+B_{g}^{\prime} Y_{i_{g}}+B_{c}^{\prime} Y_{i_{c}}}{1+B_{g}^{\prime}+B_{c}^{\prime}}
$$

$B_{c}^{\prime}$ for each point in the study is determined as a function of $T, P$, and $B_{g}^{\prime}$ from pre-computed $B^{\prime}$ tables.

The species mass fraction history data from each simulation in these studies are post-processed to identify all species that achieve a mass fraction greater than a threshold value (0.001 is used in this effort) at any time. In this way it is possible to identify important species as predicted by the baseline mechanism. Representative mass fraction histories for a selection of the most important species are presented in Fig. 5 . The normalized sensitivity coefficients from these studies are used to identify and select the most important reactions. Reactions that have a sensitivity coefficient greater than $1 \%$ of the maximum sensitivity predicted are selected as being important (this is the same criterion used by Martin et al. ${ }^{3}$ ). A representative sensitivity coefficient history is presented in Fig. 6; only reactions identified as being significant are included. Finally, any additional species required as participants in these important reactions are identified.

By collating the important species and reactions across all points in the parameter space explored in these sensitivity studies, a minimal essential set of species and reactions that can accurately model the post-combustion nozzle core flow and ablation products over the conditions of interest can be assembled. The sensitivity analysis identifies reactions involving several "large" hydrocarbon species (i.e. $\mathrm{C}_{2} \mathrm{H}_{3}, \mathrm{C}_{2} \mathrm{H}_{4}$,

Table 3. Species mass fractions for mixtures representing the nozzle edge gases (propellant gas-phase combustion products), the pyrolysis gases, and the char for the HIPPO nozzle, for use in computing initial compositions for sensitivity studies.

\begin{tabular}{cccc}
\hline Species & Edge Gas & Pyrolysis Gas & Char \\
\hline $\mathrm{HCl}$ & 0.31138 & 0.0 & 0.0 \\
$\mathrm{CO}_{2}$ & 0.29469 & 0.38968 & 0.0 \\
$\mathrm{~N}_{2}$ & 0.12603 & 0.0 & 0.0 \\
$\mathrm{H}_{2} \mathrm{O}$ & 0.15891 & 0.0 & 0.0 \\
$\mathrm{CH}_{4}$ & 0.10900 & 0.34412 & -0.44506 \\
$\mathrm{C}_{2} \mathrm{H}_{2}$ & 0.0 & 0.26620 & 1.44506 \\
\hline
\end{tabular}

7 of 18

American Institute of Aeronautics and Astronautics 


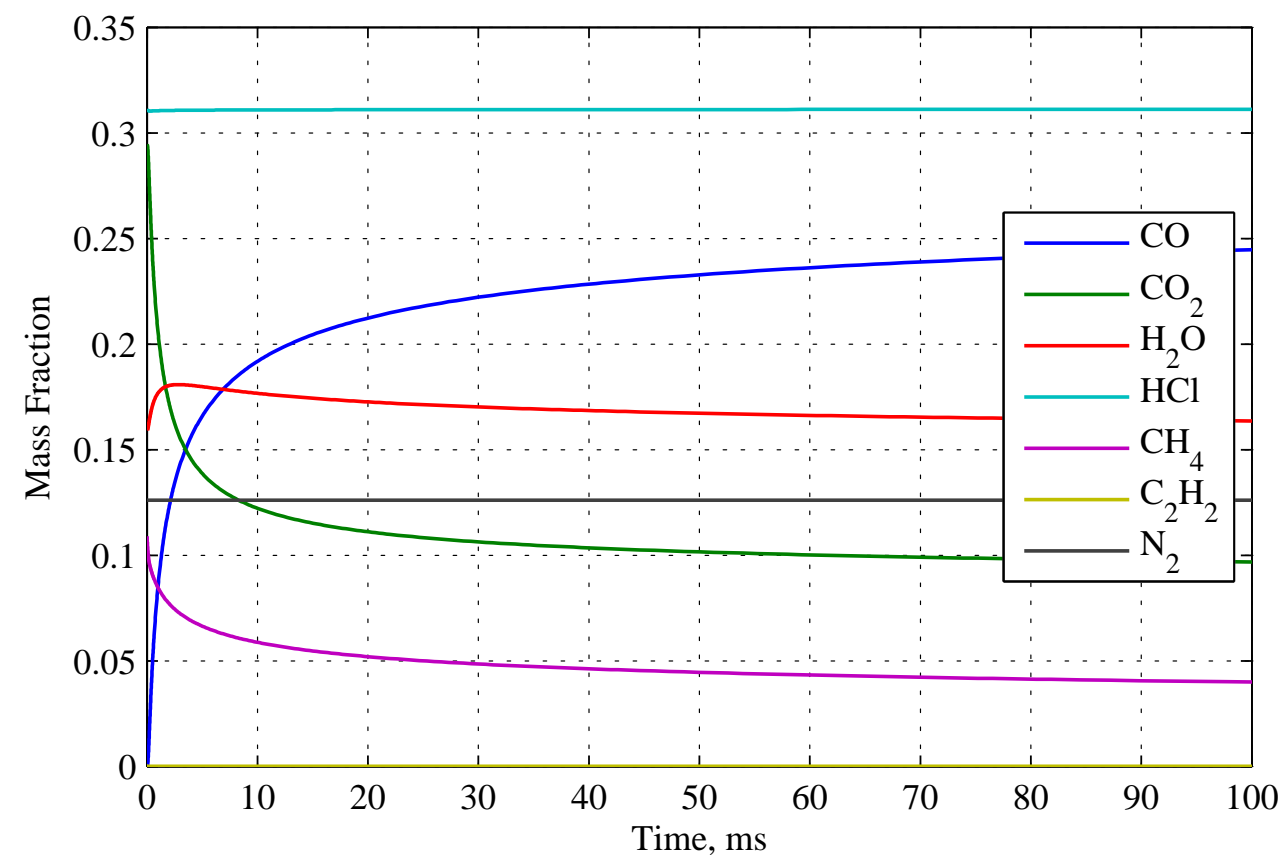

Figure 5. Mass fractions for select species as a function of time, as computed in the SENKIN analysis for a non-ablating case with $T=2500 \mathrm{~K}$ and $P=0.5 \mathrm{MPa}$.

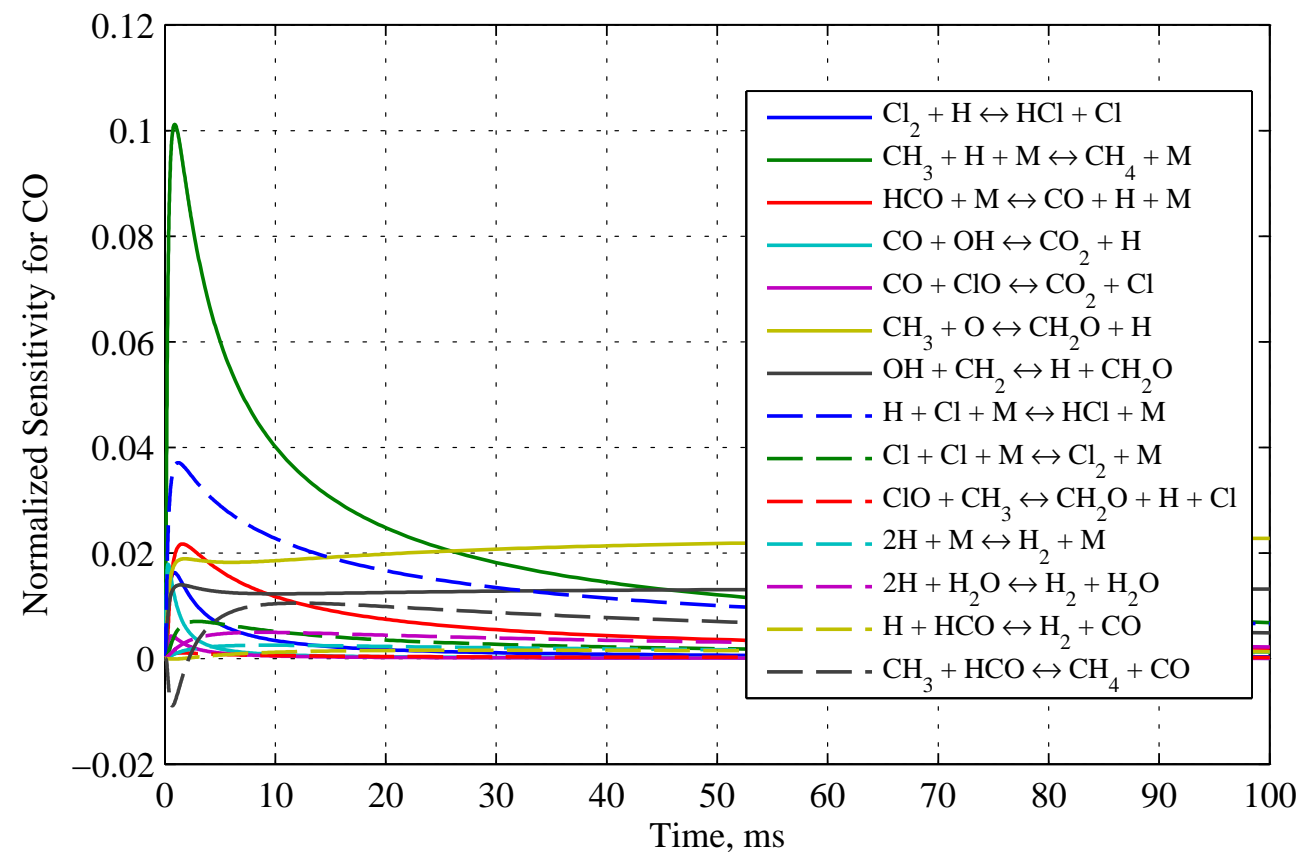

Figure 6. Normalized sensitivity coefficient for $\mathrm{CO}$ for a non-ablating case with $T=2500 \mathrm{~K}$ and $P=0.5 \mathrm{MPa}$. Only reactions with a sensitivity coefficient greater than $1 \%$ of the maximum sensitivity are plotted. 
and $\mathrm{C}_{4} \mathrm{H}_{6}$ ). However, these species and associated reactions are eliminated since the equilibrium chemistry analysis preceding the sensitivity study suggests that these species are unimportant. Comparisons of the reduced mechanism with and without these reactions indicates that removing these reactions and species has negligible impact on the results. The reduced mechanism identified here is presented in Table 1 , and features 33 reactions involving 17 gas-phase species (plus $\mathrm{N}_{2}$ as an inert gas-phase species and $\mathrm{Al}_{2} \mathrm{O}_{3}^{\star}$ as an inert condensed-phase species).

Table 4. Reduced mechanism as identified in this work.

\begin{tabular}{|c|c|c|c|c|}
\hline Index & Reaction & $A, \mathrm{~mol}-\mathrm{cm}-\mathrm{s}$ & $b$ & $T_{a}, \mathrm{~K}$ \\
\hline 1 & $\mathrm{Cl}_{2}+\mathrm{H} \rightleftharpoons \mathrm{HCl}+\mathrm{Cl}$ & $8.40 \times 10^{13}$ & 0 & 578.70 \\
\hline 2 & $\mathrm{H}_{2}+\mathrm{OH} \rightleftharpoons \mathrm{H}_{2} \mathrm{O}+\mathrm{H}$ & $2.16 \times 10^{8}$ & 1.51 & 1726.04 \\
\hline 3 & $\mathrm{C}_{2} \mathrm{H}_{2}+\mathrm{OH} \rightleftharpoons \mathrm{CH}_{3}+\mathrm{CO}$ & $4.84 \times 10^{-4}$ & 4 & -106.44 \\
\hline 4 & $\mathrm{CH}_{4}+\mathrm{Cl} \rightleftharpoons \mathrm{CH}_{3}+\mathrm{HCl}$ & $2.50 \times 10^{13}$ & 0 & 1927.33 \\
\hline 5 & $\mathrm{CH}_{4}+\mathrm{H} \rightleftharpoons \mathrm{CH}_{3}+\mathrm{H}_{2}$ & $6.60 \times 10^{8}$ & 1.62 & 5454.90 \\
\hline 6 & $\mathrm{CH}_{4}+\mathrm{OH} \rightleftharpoons \mathrm{CH}_{3}+\mathrm{H}_{2} \mathrm{O}$ & $1.00 \times 10^{8}$ & 1.6 & 1570.05 \\
\hline 7 & $\mathrm{CH}_{3}+\mathrm{H}+\mathrm{M} \rightleftharpoons \mathrm{CH}_{4}+\mathrm{M}$ & $\begin{array}{c}1.27 \times 10^{16} \\
\mathrm{CH}_{4} \text { enhanced by } 2.0 \\
\mathrm{CO} \text { enhanced by } 1.5 \\
\mathrm{CO}_{2} \text { enhanced by } 2.0 \\
\mathrm{H}_{2} \text { enhanced by } 2.0 \\
\mathrm{H}_{2} \mathrm{O} \text { enhanced by } 6.0\end{array}$ & -0.63 & 192.73 \\
\hline 8 & $\mathrm{HCO}+\mathrm{M} \rightleftharpoons \mathrm{CO}+\mathrm{H}+\mathrm{M}$ & $\begin{array}{c}1.87 \times 10^{17} \\
\mathrm{CH}_{4} \text { enhanced by } 2.0 \\
\mathrm{CO} \text { enhanced by } 1.5 \\
\mathrm{CO}_{2} \text { enhanced by } 2.0 \\
\mathrm{H}_{2} \text { enhanced by } 2.0 \\
\mathrm{H}_{2} \mathrm{O} \text { enhanced by } 0.0\end{array}$ & -1 & 8554.73 \\
\hline 9 & $\mathrm{CO}+\mathrm{OH} \rightleftharpoons \mathrm{CO}_{2}+\mathrm{H}$ & $4.76 \times 10^{7}$ & 1.23 & 35.23 \\
\hline 10 & $\mathrm{CO}+\mathrm{ClO} \rightleftharpoons \mathrm{CO}_{2}+\mathrm{Cl}$ & $3.00 \times 10^{12}$ & 0 & 503.22 \\
\hline 11 & $\mathrm{C}_{2} \mathrm{H}_{2}+\mathrm{O} \rightleftharpoons \mathrm{CH}_{2}+\mathrm{CO}$ & $1.02 \times 10^{7}$ & 2 & 956.12 \\
\hline 12 & $\mathrm{CH}_{2}+\mathrm{H}_{2} \rightleftharpoons \mathrm{CH}_{3}+\mathrm{H}$ & $5.00 \times 10^{5}$ & 2 & 3638.28 \\
\hline 13 & $\mathrm{CH}_{2}+\mathrm{H}+\mathrm{M} \rightleftharpoons \mathrm{CH}_{3}+\mathrm{M}$ & $\begin{array}{c}2.50 \times 10^{16} \\
\mathrm{CH}_{4} \text { enhanced by } 2.0 \\
\mathrm{CO} \text { enhanced by } 1.5 \\
\mathrm{CO}_{2} \text { enhanced by } 2.0 \\
\mathrm{H}_{2} \text { enhanced by } 2.0 \\
\mathrm{H}_{2} \mathrm{O} \text { enhanced by } 6.0\end{array}$ & -0.8 & 0 \\
\hline 14 & $\mathrm{CH}_{4}+\mathrm{O} \rightleftharpoons \mathrm{CH}_{3}+\mathrm{OH}$ & $1.02 \times 10^{9}$ & 1.5 & 301.93 \\
\hline 15 & $\mathrm{CH}_{3}+\mathrm{O} \rightleftharpoons \mathrm{CH}_{2} \mathrm{O}+\mathrm{H}$ & $8.43 \times 10^{13}$ & 0 & 0 \\
\hline 16 & $\mathrm{CH}_{2}+\mathrm{O} \rightleftharpoons \mathrm{H}+\mathrm{HCO}$ & $8.00 \times 10^{13}$ & 0 & 0 \\
\hline 17 & $\mathrm{OH}+\mathrm{CH}_{3} \rightleftharpoons \mathrm{CH}_{2}+\mathrm{H}_{2} \mathrm{O}$ & $5.60 \times 10^{7}$ & 1.6 & 2727.45 \\
\hline 18 & $\mathrm{OH}+\mathrm{CH}_{2} \rightleftharpoons \mathrm{H}+\mathrm{CH}_{2} \mathrm{O}$ & $2.00 \times 10^{13}$ & 0 & 0 \\
\hline 19 & $\mathrm{H}+\mathrm{Cl}+\mathrm{M} \rightleftharpoons \mathrm{HCl}+\mathrm{M}$ & $\begin{array}{c}5.30 \times 10^{21} \\
\mathrm{CH}_{4} \text { enhanced by } 2.0 \\
\mathrm{CO} \text { enhanced by } 1.5 \\
\mathrm{CO}_{2} \text { enhanced by } 2.0 \\
\mathrm{H}_{2} \text { enhanced by } 2.0\end{array}$ & -2 & -1006.44 \\
\hline
\end{tabular}

9 of 18 
Table 4. Reduced mechanism as identified in this work.

\begin{tabular}{|c|c|c|c|c|}
\hline Index & Reaction & $A, \mathrm{~mol}-\mathrm{cm}-\mathrm{s}$ & $b$ & $T_{a}, \mathrm{~K}$ \\
\hline 20 & $\mathrm{Cl}+\mathrm{Cl}+\mathrm{M} \rightleftharpoons \mathrm{Cl}_{2}+\mathrm{M}$ & $\begin{array}{c}3.34 \times 10^{14} \\
\mathrm{CH}_{4} \text { enhanced by } 2.0 \\
\mathrm{CO} \text { enhanced by } 1.5 \\
\mathrm{CO}_{2} \text { enhanced by } 2.0 \\
\mathrm{H}_{2} \text { enhanced by } 2.0\end{array}$ & 0 & -905.80 \\
\hline 21 & $\mathrm{Cl}+\mathrm{CH}_{2} \mathrm{O} \rightleftharpoons \mathrm{HCO}+\mathrm{HCl}$ & $5.00 \times 10^{13}$ & 0 & 251.61 \\
\hline 22 & $\mathrm{ClO}+\mathrm{CH}_{3} \rightleftharpoons \mathrm{CH}_{2} \mathrm{O}+\mathrm{H}+\mathrm{Cl}$ & $3.33 \times 10^{11}$ & 0.46 & 15.10 \\
\hline 23 & $\mathrm{ClO}+\mathrm{CH}_{3} \rightleftharpoons \mathrm{CH}_{2} \mathrm{O}+\mathrm{HCl}$ & $3.47 \times 10^{18}$ & -1.8 & 1041.66 \\
\hline 24 & $\mathrm{H}+\mathrm{HCl} \rightleftharpoons \mathrm{Cl}+\mathrm{H}_{2}$ & $7.94 \times 10^{12}$ & 0 & 1710.95 \\
\hline 25 & $\mathrm{HCl}+\mathrm{O} \rightleftharpoons \mathrm{Cl}+\mathrm{OH}$ & $2.30 \times 10^{11}$ & 0.64 & 452.90 \\
\hline 26 & $2 \mathrm{H}+\mathrm{M} \rightleftharpoons \mathrm{H}_{2}+\mathrm{M}$ & $1.00 \times 10^{18}$ & -1 & 0 \\
\hline 27 & $2 \mathrm{H}+\mathrm{H}_{2} \rightleftharpoons 2 \mathrm{H}_{2}$ & $9.00 \times 10^{16}$ & -0.6 & 0 \\
\hline 28 & $2 \mathrm{H}+\mathrm{H}_{2} \mathrm{O} \rightleftharpoons \mathrm{H}_{2}+\mathrm{H}_{2} \mathrm{O}$ & $6.00 \times 10^{19}$ & -1.25 & 0 \\
\hline 29 & $\mathrm{H}+\mathrm{HCO} \rightleftharpoons \mathrm{H}_{2}+\mathrm{CO}$ & $7.34 \times 10^{13}$ & 0 & 0 \\
\hline 30 & $\mathrm{OH}+\mathrm{OH} \rightleftharpoons \mathrm{H}_{2} \mathrm{O}+\mathrm{O}$ & $6.00 \times 10^{8}$ & 1.3 & 0 \\
\hline 31 & $\mathrm{CH}_{2}+\mathrm{CH}_{4} \rightleftharpoons 2 \mathrm{CH}_{3}$ & $2.46 \times 10^{6}$ & 2 & 4161.63 \\
\hline 32 & $\mathrm{CH}_{3}+\mathrm{HCO} \rightleftharpoons \mathrm{CH}_{4}+\mathrm{CO}$ & $2.65 \times 10^{13}$ & 0 & 0 \\
\hline 33 & $\mathrm{CH}_{3}+\mathrm{CH}_{2} \mathrm{O} \rightleftharpoons \mathrm{HCO}+\mathrm{CH}_{4}$ & $3.32 \times 10^{3}$ & 2.81 & 2948.87 \\
\hline
\end{tabular}

\section{III.C. Evaluation of Reduced Mechanism}

Accuracy of the reduced mechanism is assessed by repeating the SENKIN simulations, only using the reduced mechanism instead of the full mechanism. The temperature and mass fraction histories (for the species $\mathrm{CO}$, $\mathrm{CO}_{2}, \mathrm{H}_{2} \mathrm{O}, \mathrm{HCl}, \mathrm{CH}_{4}$, and $\mathrm{C}_{2} \mathrm{H}_{2}$ ) as predicted by the baseline and reduced mechanisms are compared and root mean square (RMS) differences are computed.

For the non-ablating nozzle flow study at elevated temperatures $(T>1000 \mathrm{~K})$ excellent agreement is achieved between the reduced and the baseline mechanism. RMS differences do not generally exceed $1 \%$, and for most species and points in the study the RMS difference does not exceed $0.1 \%$. However, at the lowest temperature considered $(T=1000 \mathrm{~K})$ very large RMS differences (exceeding $40 \%$ ) are encountered for $\mathrm{CO}$ and $\mathrm{C}_{2} \mathrm{H}_{2}$ (see Fig. 7). To understand this further, the $\mathrm{CO}$ mass fraction as computed by the two mechanisms is presented in Fig. 8 as a function of time for $P=0.5 \mathrm{MPa}$. While these differences seem dramatic, there are several indications suggesting that they are not that significant. First, the mass fraction for $\mathrm{CO}$ at this condition is always very small (less than $4.5 \times 10^{-6}$ ). Also, the time scale for this simulation is very long (on the order of hours) while the time scale for flow through the nozzle is very small (on the order of a few milliseconds). Additionally, the agreement between the two mechanisms is very good at the shorter timescales. Similar conclusions can be drawn for $\mathrm{C}_{2} \mathrm{H}_{2}$, but for this species the mass fractions are even smaller $\left(1.0 \times 10^{-14}\right)$. Therefore, it can be concluded that the reduced mechanism can model nozzle core flow conditions with negligible differences from the baseline mechanism.

For the study including ablation products, very good agreement is also obtained between the baseline and reduced mechanism at higher temperatures $(T>1500 \mathrm{~K})$. RMS differences are generally less than $2 \%$ for most species (often significantly less), though RMS differences as high as $6 \%$ are encountered for $\mathrm{C}_{2} \mathrm{H}_{2}$. At lower temperatures $\left(T=1500 \mathrm{~K}\right.$ ), larger differences are obtained for $\mathrm{CO}$ (up to $8 \%$ ) and $\mathrm{C}_{2} \mathrm{H}_{2}$ (up to $16 \%$ ), as illustrated in Fig. 9. The CO mass fraction as computed by the two mechanisms is presented in Fig. 10 as a function of time for $P=0.1 \mathrm{MPa}$ and $B_{g}^{\prime}=0.0$. Here the $\mathrm{CO}$ mass fraction is quite significant, so these differences cannot be dismissed quite so easily. However, the general trends and final values are the 


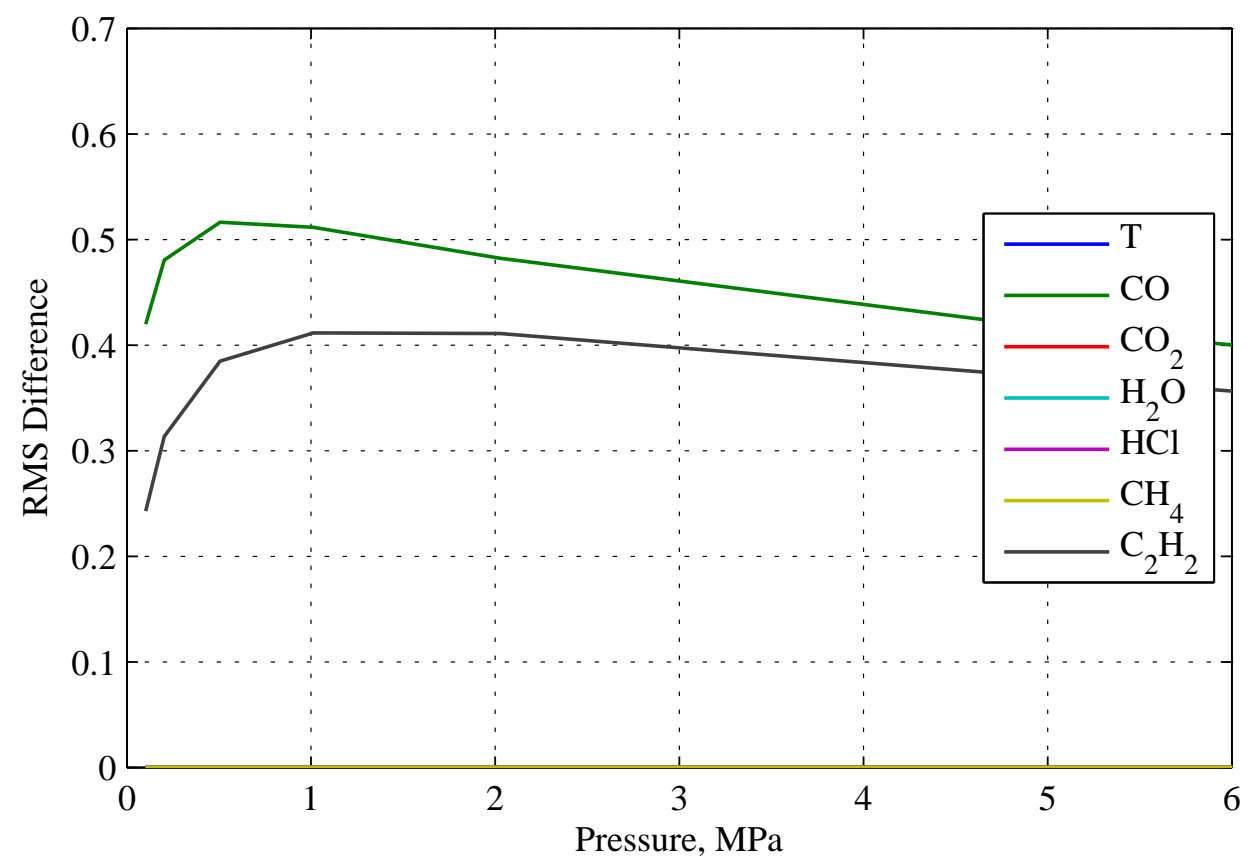

Figure 7. RMS difference between the results predicted by the baseline and reduced mechanisms as a function of pressure for a non-ablating case with $T=1000 \mathrm{~K}$.

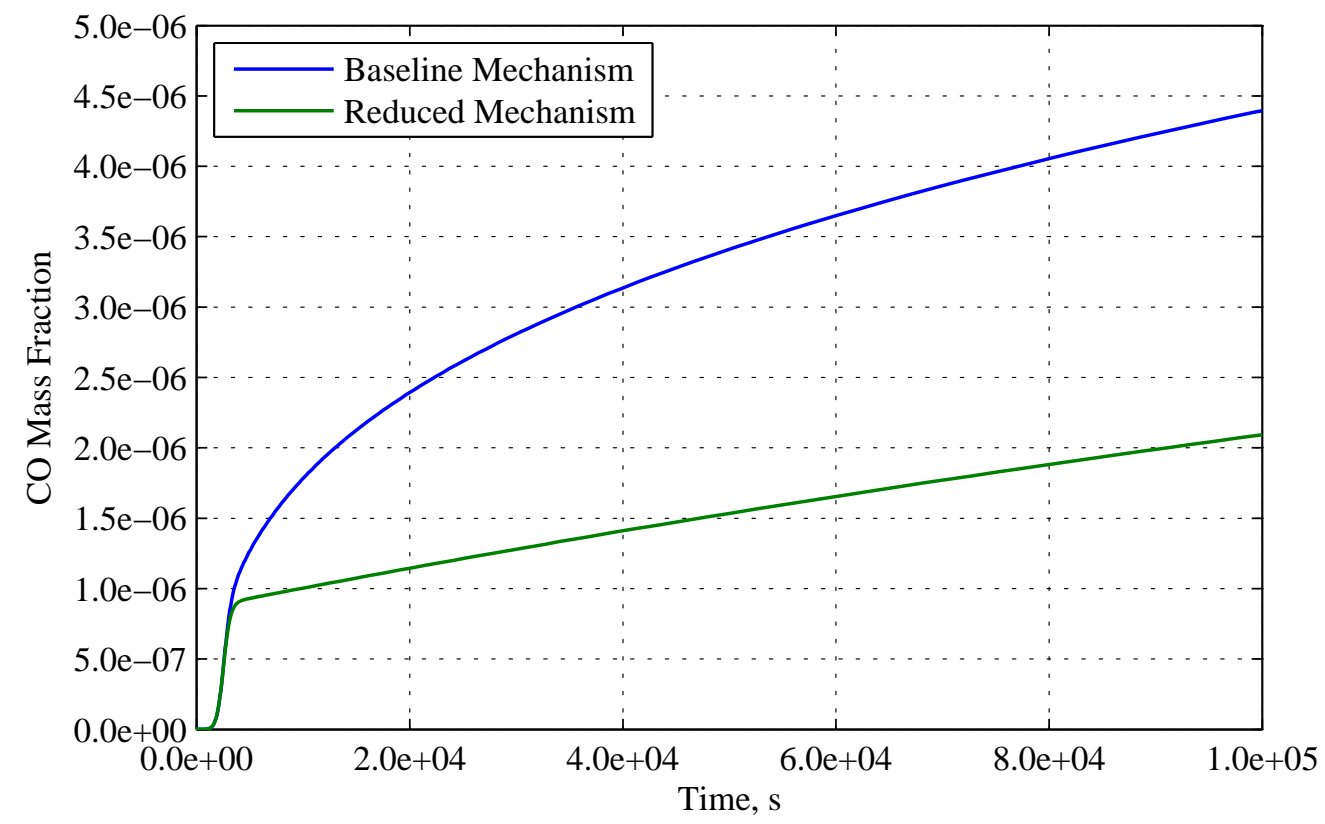

Figure 8. CO mass fraction history as predicted by the baseline and reduced mechanisms for a non-ablating case with $T=1000 \mathrm{~K}$ and $P=0.5 \mathrm{MPa}$.

11 of 18 


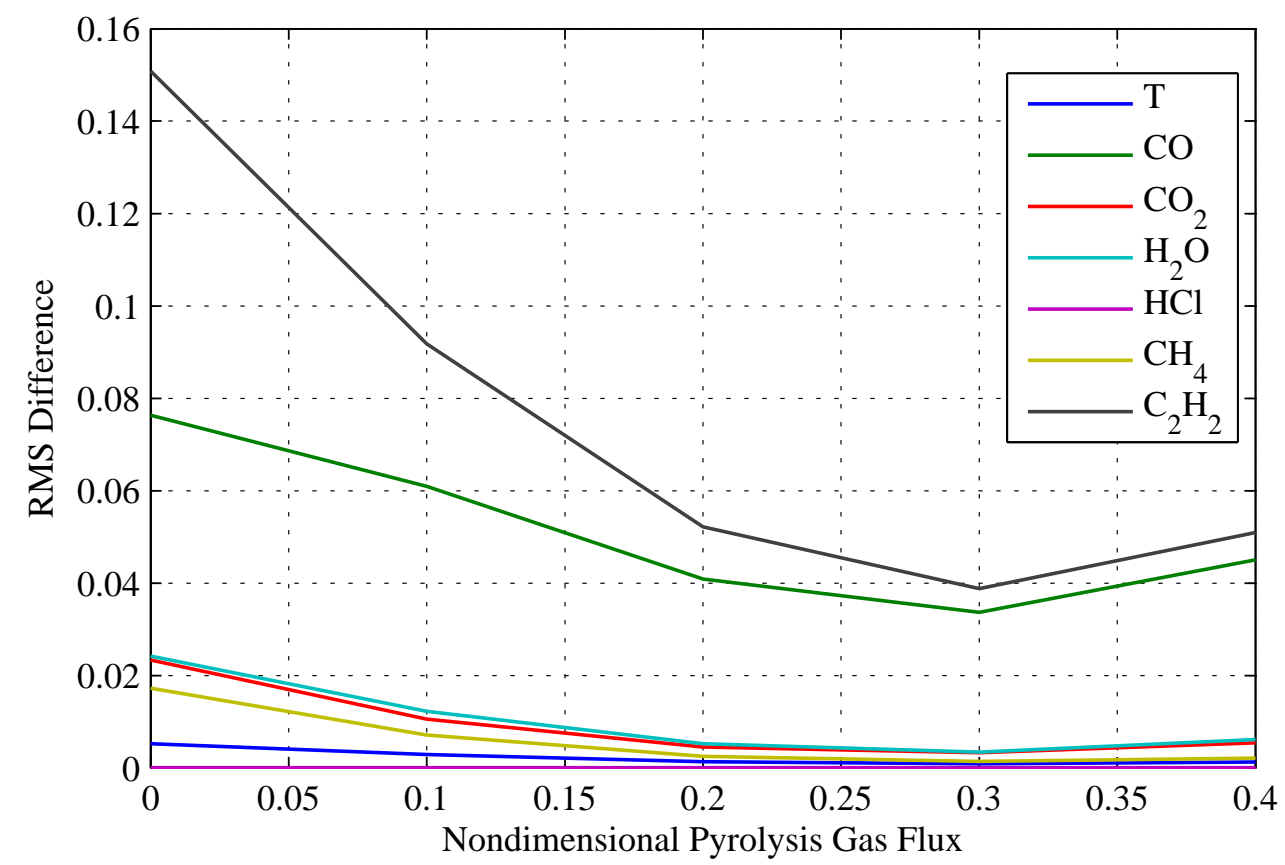

Figure 9. RMS difference between the results predicted by the baseline and reduced mechanisms as a function of nondimensional pyrolysis gas flux for an ablating case with $T=1500 \mathrm{~K}$ and $P=0.1 \mathrm{MPa}$.

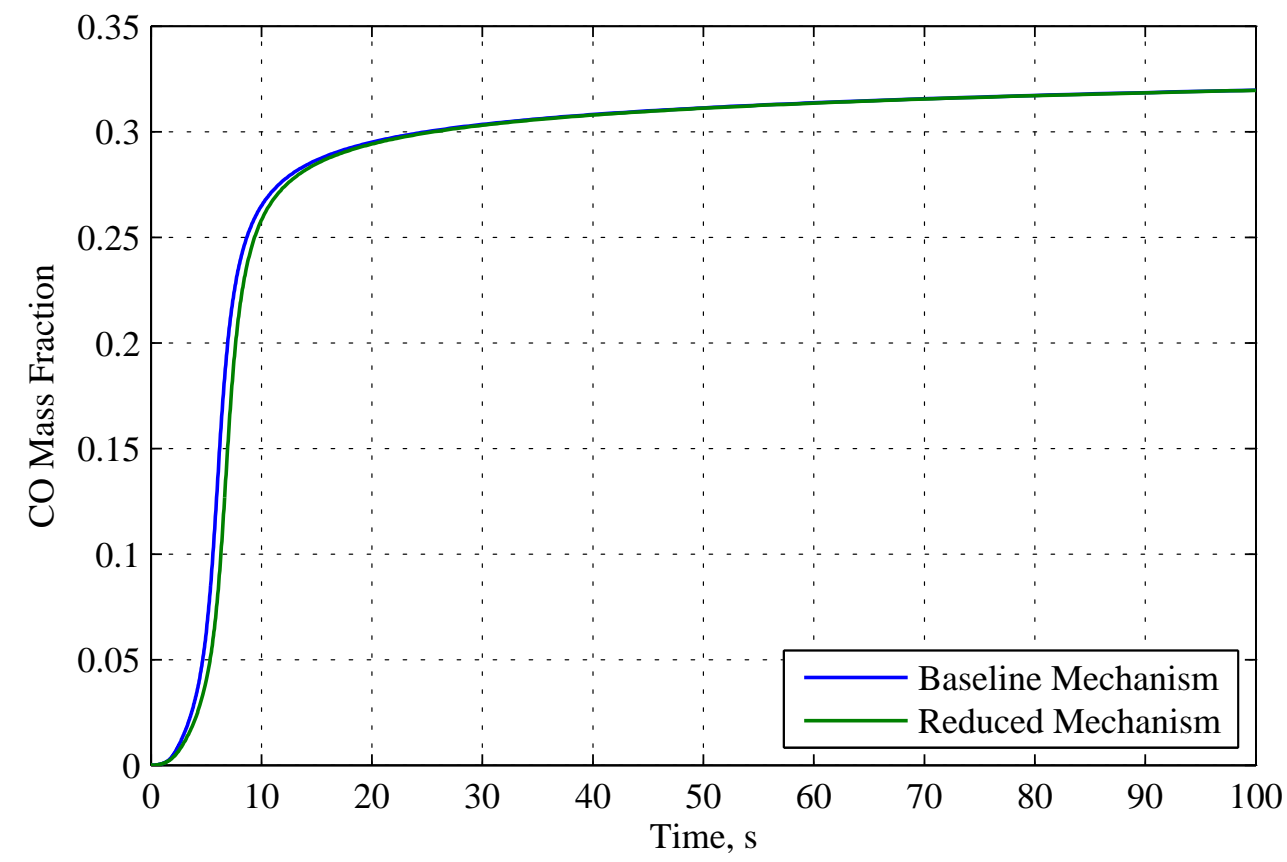

Figure 10. CO mass fraction history as predicted by the baseline and reduced mechanisms for an ablating case with $T=1500 \mathrm{~K}, P=0.1 \mathrm{MPa}$, and $B_{g}^{\prime}=0.0$. 


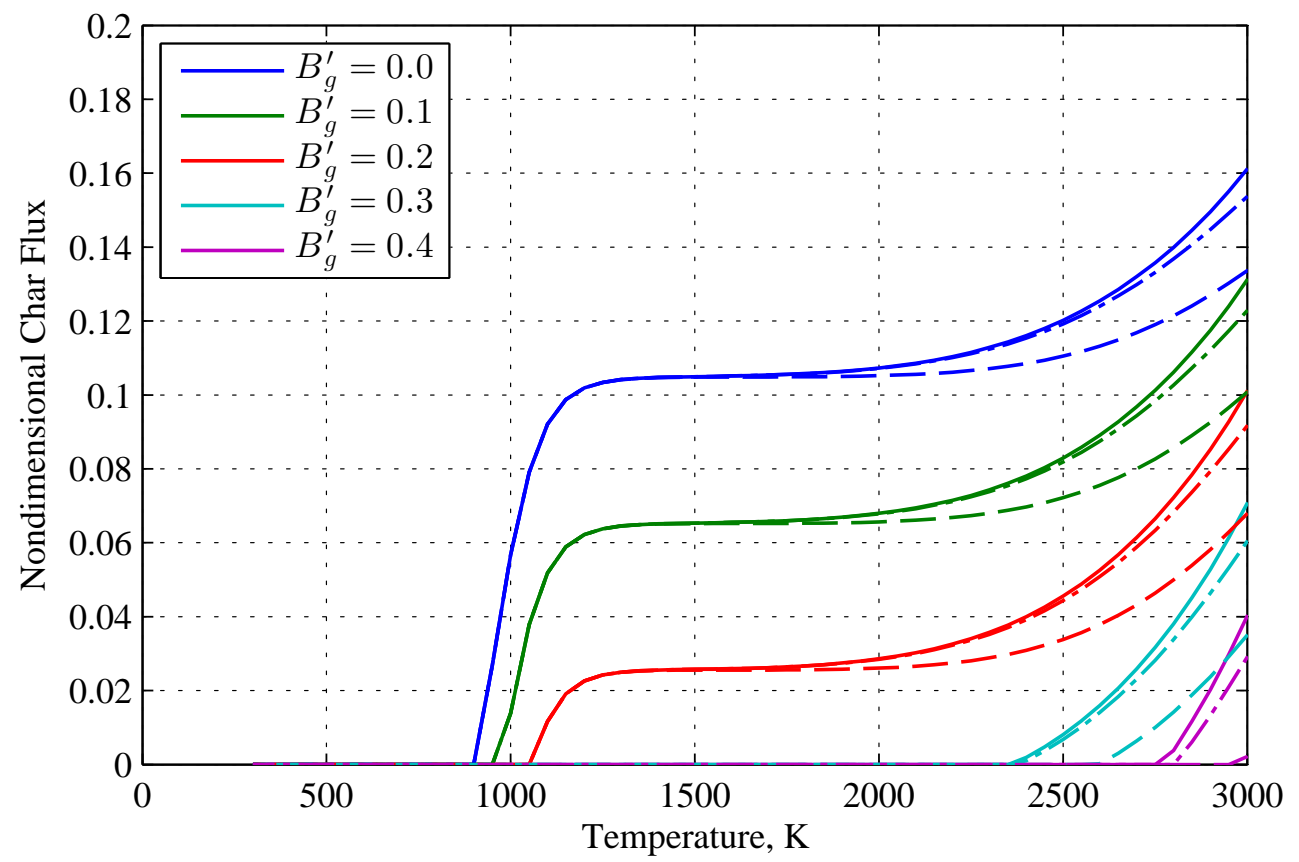

Figure 11. Comparison of $B^{\prime}$ tables computed using three different species sets, for $P=0.1 \mathrm{MPa}$. Solid lines represent results computed using all relevant species from the CEA thermodynamics database; dashed lines represent results computed using only the 18 gas-phase species initially identified as part of the mechanism reduction effort; dash-dotted lines represent results computed using these 18 species plus HCN.

same for both mechanisms; only a small shift in time is observed, but this occurs at time scales much longer than would be experienced in a nozzle application. The same conclusions can be drawn for $\mathrm{C}_{2} \mathrm{H}_{2}$.

This reduced mechanism is further evaluated by investigating the ability of this reduced species set to produce accurate $B^{\prime}$ tables. $B^{\prime}$ tables are computed using the Chemics code two different ways: without restriction on the species (i.e. using all the species in the underlying thermodynamic database), and with only the 18 gas-phase species in the reduced mechanism. These two $B^{\prime}$ tables are compared in Fig. 11, where it can be seen that there are significant differences for $T>2000 \mathrm{~K}$. Clearly, using only these 18 species is not sufficient for modeling ablation. This discrepancy is largely due to the absence of HCN, which was identified in section II.C as being a potentially important species, from the reduced mechanism. When HCN is added to the reduced mechanism as an inert species, much better agreement is obtained for the $B^{\prime}$ tables (see Fig. 11). The accuracy thus achieved is believed to be acceptable; further improvement can only be made by the addition of multiple species, which comes at significant computational cost.

\section{III.D. Final Reduced Mechanism}

The final reduced mechanism comprises the 33 reactions listed in Table 4 and 20 species:

$$
\mathrm{C}_{2} \mathrm{H}_{2}, \mathrm{CH}_{2} \mathrm{O}, \mathrm{CH}_{2}, \mathrm{CH}_{3}, \mathrm{CH}_{4}, \mathrm{CO}, \mathrm{CO}_{2}, \mathrm{Cl}, \mathrm{Cl}_{2}, \mathrm{ClO}, \mathrm{H}, \mathrm{H}_{2}, \mathrm{H}_{2} \mathrm{O}, \mathrm{HCN}, \mathrm{HCO}, \mathrm{HCl}, \mathrm{N}_{2}, \mathrm{O}, \mathrm{OH}, \mathrm{Al}_{2} \mathrm{O}_{3}^{\star}
$$

Note that $\mathrm{N}_{2}$ and $\mathrm{HCN}$ are inert gas-phase species, while $\mathrm{Al}_{2} \mathrm{O}_{3}^{\star}$ is an inert condensed-phase species. Reaction rates are computed using a modified Arrhenius equation:

$$
k=A T^{b} \exp \left(-T_{a} / T\right)
$$

The evaluation presented in section III.C suggests that the reduced mechanism identified here adequately reproduces predictions obtained with the baseline mechanism, and is sufficient for use in conjugate flowfield / ablation simulations of carbon-phenolic nozzles for solid rocket motors using typical aluminized AP / HTPB propellants. At higher temperatures there is negligible difference in the results between the two mechanisms. While the differences are larger at lower temperatures, these are judged to be acceptable, especially considering that low temperatures are only encountered in small regions of the flowfield (near the wall) for very short periods of time at the start of motor operation. Since the reduced mechanism includes 
approximately half the species and one quarter the number of reactions present in the baseline mechanism, flowfield calculations utilizing the reduced mechanism will require significantly less computational resources and time for completion.

\section{HIPPO Nozzle Flowfield Analysis}

The 20 species reduced mechanism identified in this work is used in conjunction with the LeMANS flow solver to compute the flow through the HIPPO nozzle. Results are compared to those obtained with the 13 species mechanism proposed by Troyes, and to a reference solution obtained with the Chemics chemical equilibrium solver. The nozzle chamber conditions are $P_{0}=4.48 \mathrm{MPa}$ and $T_{0}=3452 \mathrm{~K}$; wall temperature is $2500 \mathrm{~K}$.

The mesh has 77 cells in the wall-normal direction and 150 cells in the axial direction, for a total of 11,550 cells. Near wall cell thickness ranges from approximately $6.2 \times 10^{-8} \mathrm{~m}$ at the throat increasing to $2.0 \times 10^{-7} \mathrm{~m}$ at the exit; a stretch ratio of $20 \%$ is used in the wall-normal direction. Wall $Y^{+}$values remain below 0.1 for the length of the nozzle with this mesh. The axial dimension of the cells ranges from approximately $1.27 \times 10^{-3} \mathrm{~m}$ near the throat and nose increasing to $6.8 \times 10^{-3} \mathrm{~m}$ at the exit. Biasing is used in order to obtain a smooth mesh. Mesh parameters are determined from an extensive mesh refinement study, which suggests that this mesh can yield heat flux values with an error of less than $0.5 \%$. The mesh is illustrated in Fig. 1.

Wall heat flux as computed with the two mechanisms is compared in Fig. 12. Agreement between the two mechanisms is quite good, with an RMS difference of $1.2 \%$. Flowfield parameters along the nozzle centerline are also compared. Pressure, temperature, and velocity are in excellent agreement, with RMS differences less than $0.4 \%$. Mass fractions for the twelve species in common between the two mechanisms are compared in Fig. 13. The agreement for most species is quite good, with the largest discrepancies occurring in the downstream portion of the nozzle. The most significant discrepancy occurs for $\mathrm{CO}_{2}$.

The mass fraction for $\mathrm{CO}_{2}$ is presented in Fig. 14, and is compared to the equilibrium solution computed using Chemics and to results from two additional LeMANS simulations. These simulations modeled chemical equilibrium by increasing the forward and backward reaction rates by a factor of 1000 . It can be seen that the mass fraction for $\mathrm{CO}_{2}$ as predicted using finite-rate chemistry and the 13 species mechanism is essentially

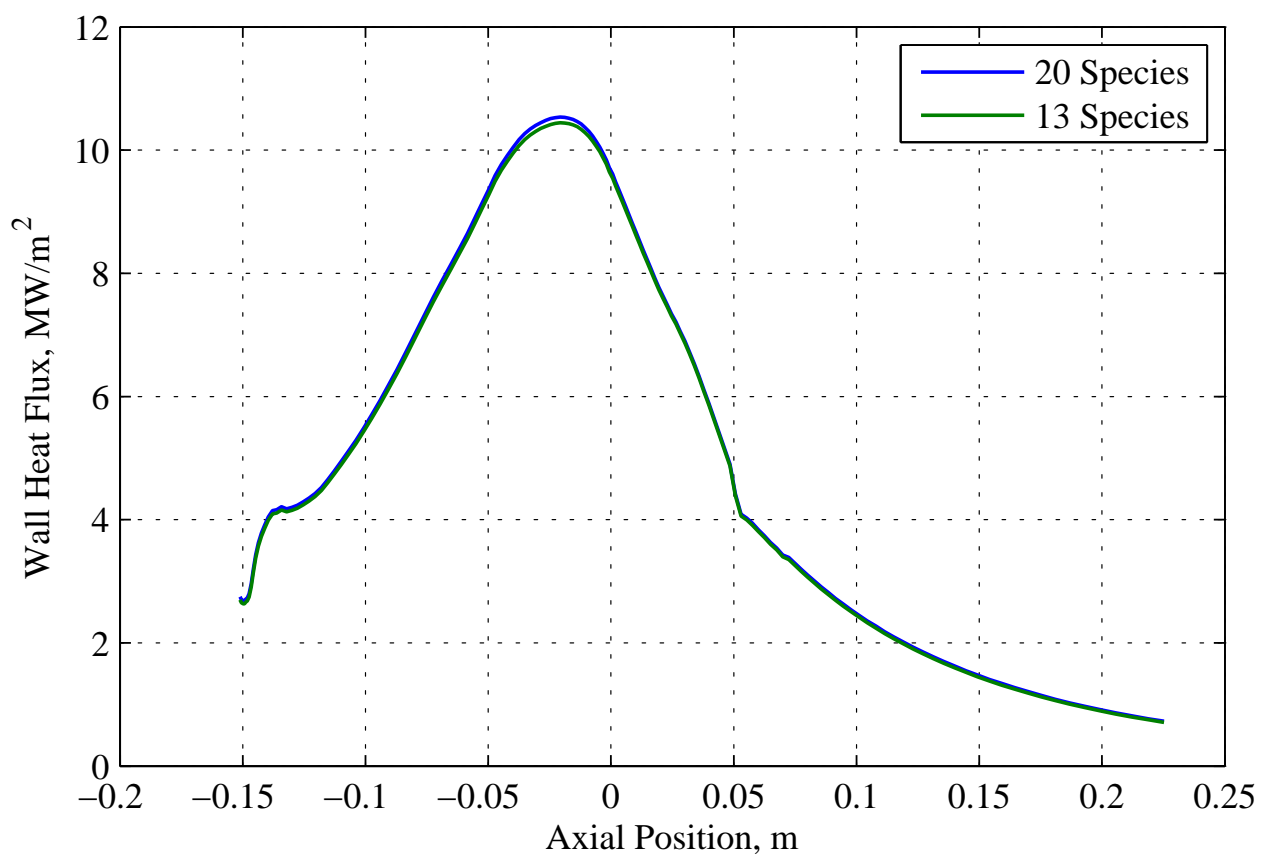

Figure 12. Heat flux on the wall of the HIPPO nozzle, plotted as a function of axial position. Blue line represents results from a LeMANS simulation using the 20 species reduced mechanism identified in this effort; the green line represents results from a simulation using the 13 species mechanism proposed by Troyes. 


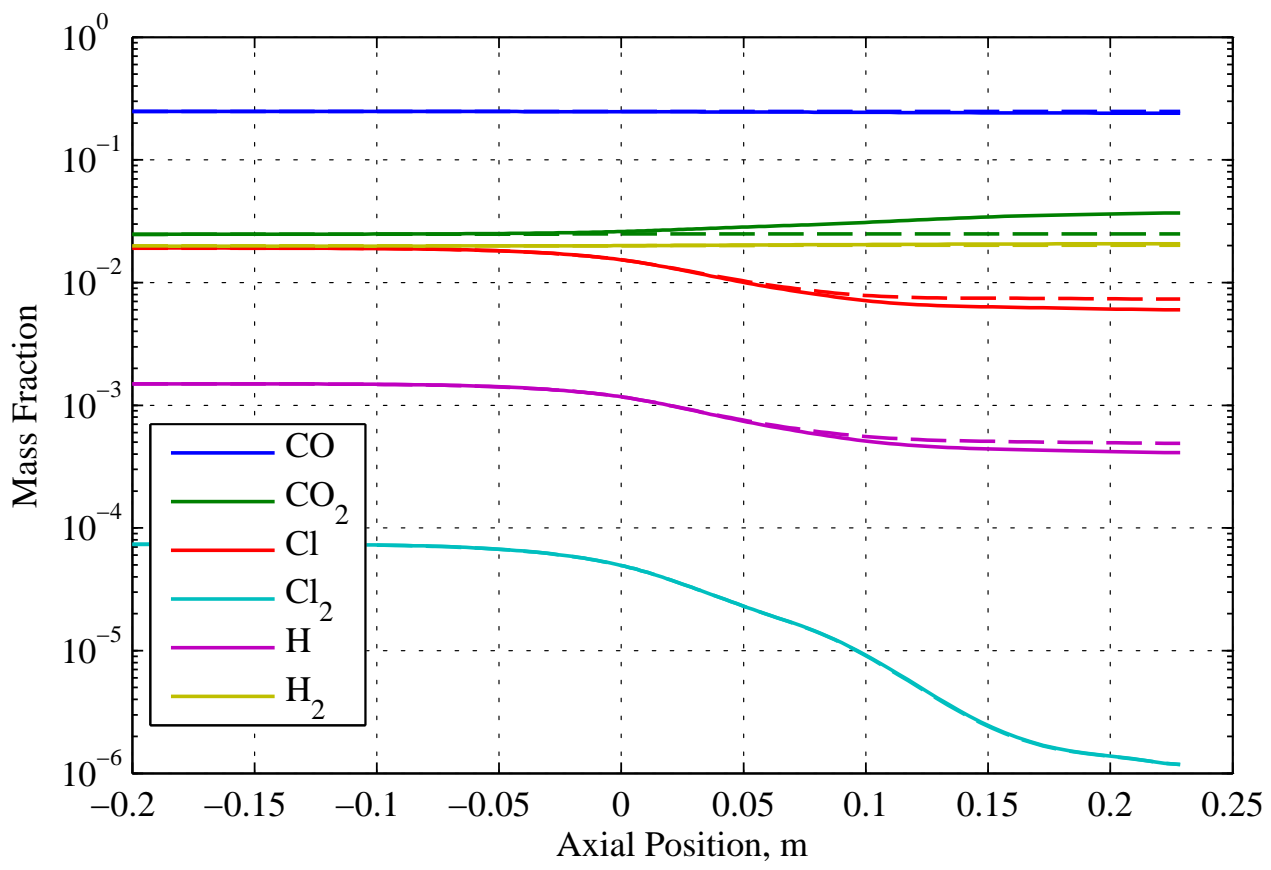

(a) First six species.

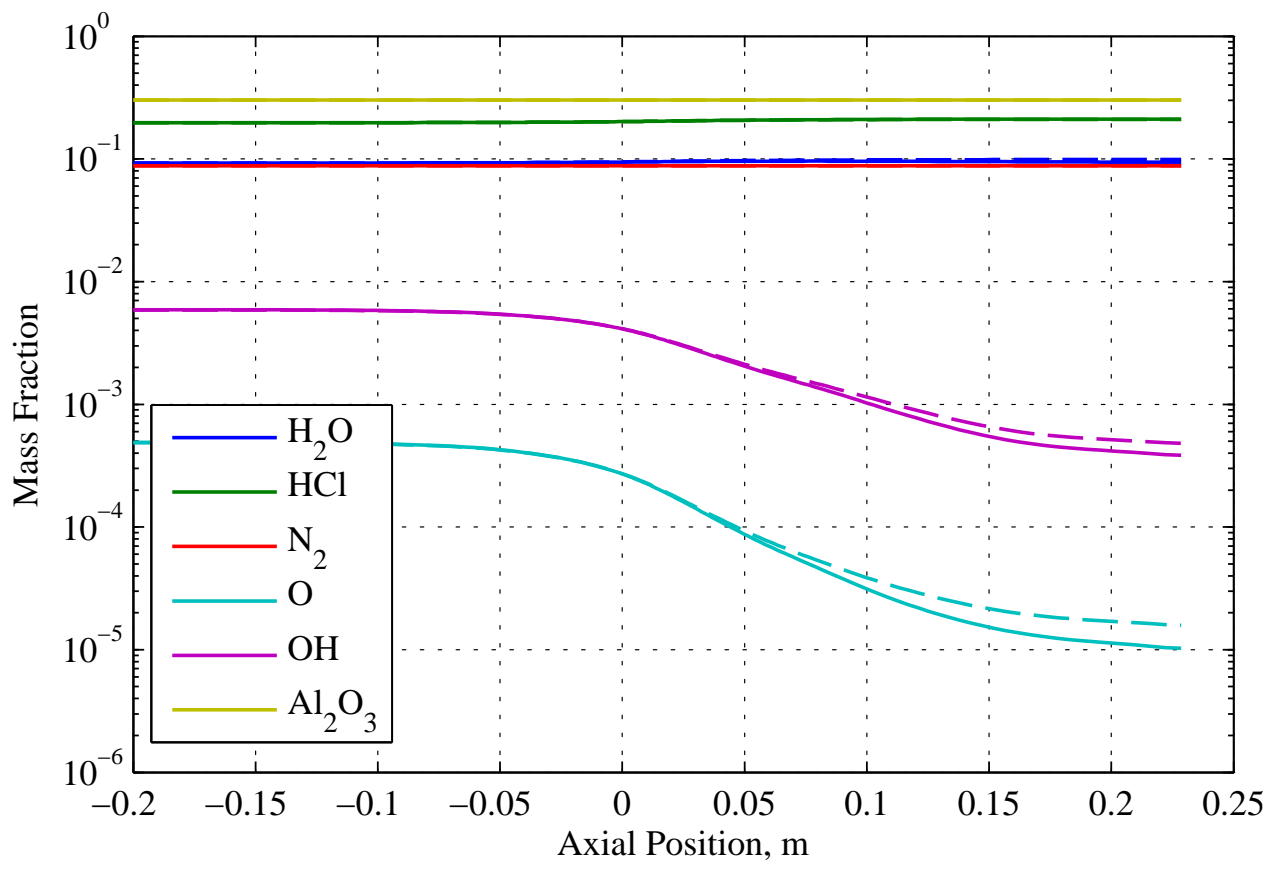

(b) Last six species.

Figure 13. Species mass fractions on the centerline of the HIPPO nozzle, plotted as a function of axial position. Solid lines mark LeMANS results using the 20 species reduced mechanism identified in this effort; dashed lines indicate LeMANS results using the 13 species mechanism proposed by Troyes. 


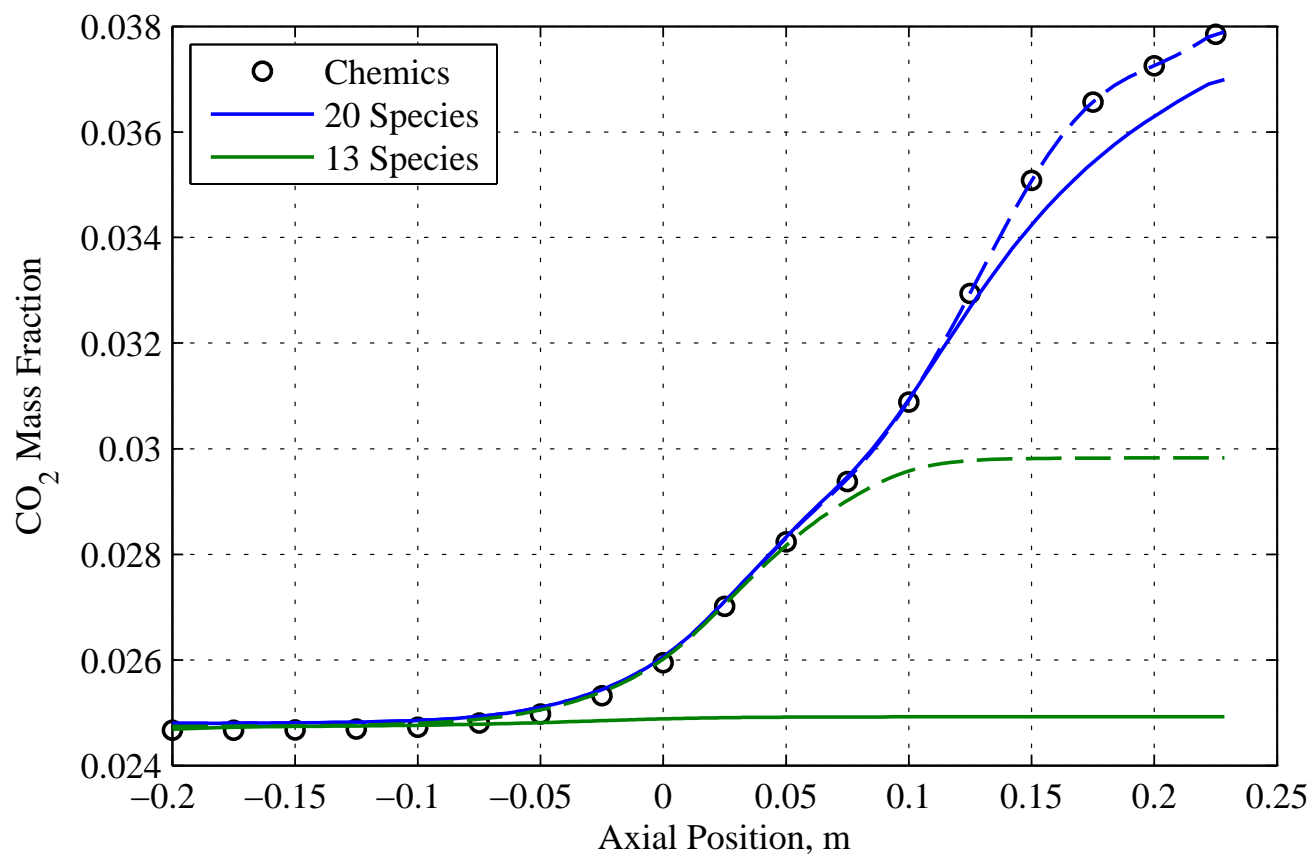

Figure 14. Mass fraction for $\mathrm{CO}_{2}$ on the centerline of the HIPPO nozzle, plotted as a function of axial position. Symbols represent the Chemics reference solution, solid lines mark LeMANS results assuming finite-rate chemistry, and dashed lines indicate LeMANS results assuming equilibrium chemistry.

"frozen" and nearly constant throughout the nozzle. In contrast to this, the finite-rate chemistry simulation using the 20 species mechanism shows significant changes to the mass fraction for $\mathrm{CO}_{2}$, largely following the reference chemical equilibrium solution. The equilibrium chemistry simulation using the 20 species mechanism is in excellent agreement with the reference equilibrium solution, but the equilibrium simulation using the 13 species mechanism is in poor agreement. Similar observations can be made for other species (CO in particular), though to a lesser extent.

While it is expected that chemical non-equilibrium may become noticeable in the downstream portion of the nozzle (where temperature and pressures are dropping significantly), it is expected that chemical equilibrium would prevail in the upstream (subsonic) portion of the nozzle. However, the 13 species mechanism predicts significant chemical nonequilibrium for $\mathrm{CO}_{2}$ and $\mathrm{CO}$ beginning upstream of the throat. In contrast, the 20 species mechanism predicts that significant chemical nonequilibrium begins far downstream of the throat, for all species. The 20 species mechanism is therefore in better agreement with expectations. Additionally, the 20 species mechanism can be used to obtain the correct equilibrium solution, whereas the 13 species mechanism cannot. The proposed mechanism therefore improves upon the Troyes mechanism, though at the cost of increased computational expense.

These simulations show that the reduced mechanism identified in this work is adequate for modeling the flow through the nozzles of solid rocket motors using typical aluminized AP / HTPB propellants. It is further believed that this mechanism is suitable for use in coupled flowfield / ablation analyses of carbon-phenolic nozzles, subject to the following restrictions:

$$
\begin{gathered}
B_{g}^{\prime} \leq 0.4 \\
T \leq 3000 \mathrm{~K} \\
P \leq 6.0 \mathrm{MPa}
\end{gathered}
$$

Should it be necessary to model regions outside of this parameter space, it may be necessary to expand the mechanism with additional species and / or reactions. 


\section{Conclusion}

A new reduced, gas-phase finite-rate chemistry mechanism suitable for use in computational fluid dynamics (CFD) analyses of ablation within rocket nozzles has been proposed. The small size of this mechanism (20 species and 33 reactions) makes it quite affordable and suitable for CFD applications, yet is comparable in accuracy over the parameter space of interest to a much larger, detailed mechanism that is commonly used to model combustion of solid rocket propellants. The proposed mechanism was produced by reducing the detailed mechanism based on a linear sensitivity analysis. This sensitivity analysis identified the species and reactions that had the strongest impact on the solution for a range of ablating and non-ablating conditions. Unimportant species and reactions were then eliminated with minimal impact to accuracy.

The flow through the HIPPO nozzle was computed with the LeMANS flow solver using the proposed 20 species mechanism as well as a 13 species mechanism from the literature. Comparisons were also made to an equilibrium chemistry reference solution. Results obtained with the 20 species mechanism agreed well with the reference solution and showed improvement over those produced with the 13 species mechanism. This mechanism was therefore found to be adequate for modeling nozzle flows involving typical aluminized AP/HTPB propellants.

The reduced mechanism presented in this paper provides a key component, previously missing, that will enable conjugate analyses of ablation in rocket nozzles to be performed. The proposed mechanism is suitable for use in coupled flowfield/ablation analyses of carbon-phenolic nozzles for the parameter space: $B_{g}^{\prime} \leq 0.4$, $T \leq 3000 \mathrm{~K}$, and $P \leq 6.0 \mathrm{MPa}$. In future work, this new mechanism will be used as part of conjugate ablation analyses of the HIPPO nozzle.

\section{Acknowledgments}

Funding for this work was provided by the NAWCWD Fellowship Program, the SMART Scholarship, and NAWCWD IAR 5097. Computational resources were provided in part by the Department of Defense High Performance Computing Modernization Office. Thanks are extended to Dr. Matthew Gross for discussions regarding the "reduced Jeppson" mechanism.

\section{References}

\footnotetext{
${ }^{1}$ Troyes, J., Dubois, I., Borie, V., and Boischot, A., "Multi-Phase Reactive Numerical Simulations of a Model Solid Rocket Exhaust Jet," 42nd AIAA/ASME/SAE/ASEE Joint Propulsion Conference ES Exhibit, July 2006, AIAA 2003-4414.

${ }^{2}$ Cross, P. G. and Boyd, I. D., "Two-Dimensional Modeling of Ablation and Pyrolysis with Application to Rocket Nozzles," Journal of Spacecraft and Rockets, Vol. 54, No. 1, January 2017, pp. 212-224.

${ }^{3}$ Martin, A., Cozmuta, I., Wright, M. J., and Boyd, I. D., "Kinetic Rates for Gas-Phase Chemistry of Phenolic-Based Carbon Ablator in Atmospheric Air," Journal of Thermophysics and Heat Transfer, Vol. 29, No. 2, Apr 2015, pp. 222-240.

${ }^{4}$ Gökçen, T., "N2-CH4-Ar Chemical Kinetic Model for Simulations of Atmospheric Entry to Titan," Journal of Thermophysics and Heat Transfer, Vol. 21, No. 1, January 2007, pp. 9-18.

${ }^{5}$ Arnold, J., Dodson, J., and Laub, B., "Subscale Solid Motor Nozzle Tests - Phase IV and Nozzle Materials Screening and Thermal Characterization - Phase V," NASA CR 161254, NASA, June 1979.

${ }^{6}$ Scalabrin, L. C., Numerical Simulation of Weakly Ionized Hypersonic Flow Over Reentry Capsules, Ph.D. thesis, University of Michigan, Ann Arbor, MI, 2007.

${ }^{7}$ Wiebenga, J. E., High-Fidelity Material Response Modeling as Part of an Aerothermoelastic Framework for Hypersonic Flows, Ph.D. thesis, University of Michigan, Ann Arbor, MI, 2014.

${ }^{8}$ Ewing, M. E. and Isaac, D. A., "Mathematical Modeling of Multiphase Chemical Equilibrium," Journal of Thermophysics and Heat Transfer, Vol. 29, No. 3, July 2015, pp. 551-562.

${ }^{9}$ McBride, B. J. and Gordon, S., "Computer Program for Calculation of Complex Chemical Equilibrium Compositions and Applications. Part 2: User's Manual and Program Description," NASA RP-1311-P2, NASA, June 1996.

${ }^{10}$ Gross, M. L. and Beckstead, M. W., "Diffusion Flame Calculations for Composite Propellants Using a Vorticity-Velocity Formulation," Journal of Propulsion and Power, Vol. 25, No. 1, January 2009, pp. 74-82.

${ }^{11}$ Gross, M. L. and Beckstead, M. W., "Diffusion flame calculations for composite propellants predicting particle-size effects," Combustion and Flame, Vol. 157, No. 5, May 2010, pp. 864-873.

${ }^{12}$ Cheng, C., Bao, F. T., Zhao, Y., and Xu, H., "Premixed Combustion of a Fine AP/HTPB Composite Propellant Based on Detailed Chemical Kinetics," Applied Mechanics and Materials, Vol. 390, August 2013, pp. 320-326.

${ }^{13}$ Gross, M. L., Two-Dimensional Modeling of AP/HTPB Utilizing a Vorticity Formulation and One-Dimensional Modeling of $A P$ and $A D N$, Ph.D. thesis, Brigham Young University, 2007.

${ }^{14}$ Lutz, A. E., Kee, R. J., and Miller, J. A., "SENKIN: A Fortran Program for Predicting Homogeneous Gas Phase Chemical Kinetics with Sensitivity Analysis," Sandia Report SAND87-8248, Sandia, 1988.
} 
${ }^{15}$ Kee, R. J., Rupley, F. M., and Miller, J. A., "CHEMKIN-II: A Fortran Chemical Kinetics Package for the Analysis of Gas-Phase Chemical Kinetics," Sandia Report SAND89-8009B, Sandia, 1991.

${ }^{16}$ Milos, F. and Chen, Y.-K., "Ablation, Thermal Response, and Chemistry Program for Analysis of Thermal Protection Systems," 10th AIAA/ASME Joint Thermophysics and Heat Transfer Conference, June 2010, AIAA 2010-4663.

${ }^{17}$ Blackwell, B. and Howard, M., "An Element Potential Based Chemical Equilibrium Solver for Gas/Surface Thermochemistry," 50th AIAA Aerospace Sciences Meeting including the New Horizons Forum and Aerospace Exposition, January 2012, AIAA 2012-0815.

\section{8 of 18}


This article has been cited by:

1. Peter G. Cross, Iain D. Boyd. Conjugate Analysis of Rocket Nozzle Ablation . [Citation] [PDF] [PDF Plus] 